\title{
Determination of the optimal working fluid for the turbine recovering combustion engine exhaust gases heat
}

\author{
Yury Matveev ${ }^{1, *}$, Marina Cherkasova ${ }^{1}$, Viktor Rassokhin ${ }^{1}$, Kirill Lapshin ${ }^{1}$, Nikolay \\ Kortikov $^{1}$, Rostislav Ivanovski ${ }^{1}$, Evgenii Yurevich ${ }^{1}$, Sergey Vokhmyanin ${ }^{1}$, Viktor Popov ${ }^{1}$, and \\ Irina Akhmetova ${ }^{2}$ \\ ${ }^{1}$ Peter the Great St.Petersburg Polytechnic University, Polytechnicheskaya, 29, St. Petersburg, 195251, \\ Russia \\ ${ }^{2}$ Kazan State Power Engineering University, Kazan, Russian Federation
}

\begin{abstract}
Microsteam turbine implementation for combustion engine exhaust gases heat recovery and subsequent acquisition of additional power is being investigated in many developed countries of the world. The results of such studies have already found application in some trucks. But this type of turbines is very weak in the Russian market. Turbine installation behind the combustion engine works under conditions of low volumetric flow of work fluid. This leads to a decrease in the height of the blade and vane wheels flow passage and an increase of the relative values of the gaps in the seals which are the reasons for the growth of the working fluid leakages. High degree of pressure reduction when selecting single-stage turbine leads to a supersonic velocity in the flow passage and an increase of the losses due to powerful shock waves. The efficiency of the turbine installation under these operating conditions is low and requires additional investigations. In this work, the working fluids which can give the greatest efficiency of the turbine installation were investigated. It was shown that not only thermodynamic but also hazardous and economic parameters must be taken into consideration. Working fluid with the high thermodynamic efficiency was compared with the one that profitable from economic point of view. The most appropriate substance was chosen and implemented in the microsteam turbine. The turbine stage which allows increasing economy and ecological compatibility of the combustion engine was developed and optimized by analytical methods.
\end{abstract}

\section{Introduction}

Many factors affect the choice of working fluid for organic Rankin cycle (ORC) such as energy source, working temperature range, pressure and power level of the turbine installation. The choice of working fluid for ORC is considered in the many works [1-6]. Thermodynamic cycle model is often used to compare the characteristics of working fluids. This is an important criterion of comparison and essentially depends on the physicochemical

\footnotetext{
*Corresponding author: matyury@mail.ru
} 
properties of the working fluid. However, working fluid with high thermal efficiency may require conditions that lead to high costs. For instance, the use of water demands heaters with high temperature and pressure in the cycle. Therefore, the use of steam in the cycle is effectually only at relatively high power. As a result, the problem of choosing the optimal substance is multicriteria and has been considered in a number of works [7, 8]. A review of the literature on the suitable working fluids for combustion engine exhaust gases heat recovery has shown that methanol, isopentane, ethanol, water, R245fa, oktamethyltrisiloxane are the most suitable for examination and comparison [9-12]. Further working fluids deeper investigation [13-15] and application in the turbine installation was carried out on the basis of [16-20].

\section{Methods}

When choosing a working fluid, it is important to take into account that the specific temperature for a given working fluid must be a maximum. High value of the heat transfer coefficient and low friction losses should be provided with a low viscosity of the liquid and vapor phases [21]. Working fluid must have a high thermal conductivity to ensure efficient heating and cooling in the heat exchanger. An important requirement for the working fluid is thermal stability in the high temperature range, since many organic compounds undergo chemical transformation upon heating, which lead to a change in the properties of the fluid [22-29]. More than that, fluid should not be flammable, toxic or pollute the environment. Thermal analysis was carried out to determine the optima working fluid. The evaluation was conducted on the basis of the cycle thermal efficiency which was calculated by the formula (1):

$$
\eta=\frac{\left(h_{1}-h_{2}\right) n_{0}}{h_{1}}
$$

where $h_{1,2}$ - turbine inlet and outlet enthalpy, $n_{0}$ - adiabatic process coefficient, here is 0.96 .

Inlet pressure $\left(P_{0}\right)$, inlet temperature $\left(T_{0}\right)$ and outlet pressure $\left(P_{2}\right)$ were ranged during thermodynamic analysis. As a result, the most effective working fluids for organic Rankin cycle with the chosen range are methanol and isopentane. This is shown in Fig. 1 and Fig. 2. In spite of the high efficiency, methanol is highly hazardous substance with the second hazard class. Criteria for the classification of hazardous waste in the second class of hazard - the ecological system is badly disturbed; recovery period after complete elimination of the harmful effects source for at least 30 years. In light of the above, isopentane was chosen for further investigation.

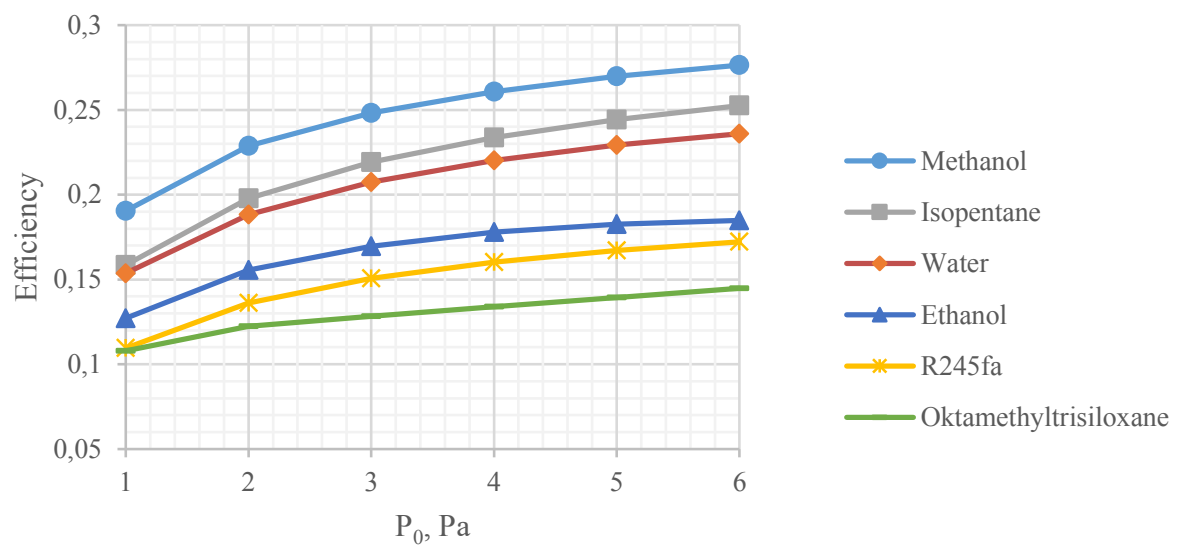

Fig. 1. Dependence of efficiency on the turbine inlet pressure at $\mathrm{T} 0=550 \mathrm{~K}, \mathrm{p} 2=0.081 \mathrm{MPa}$. 


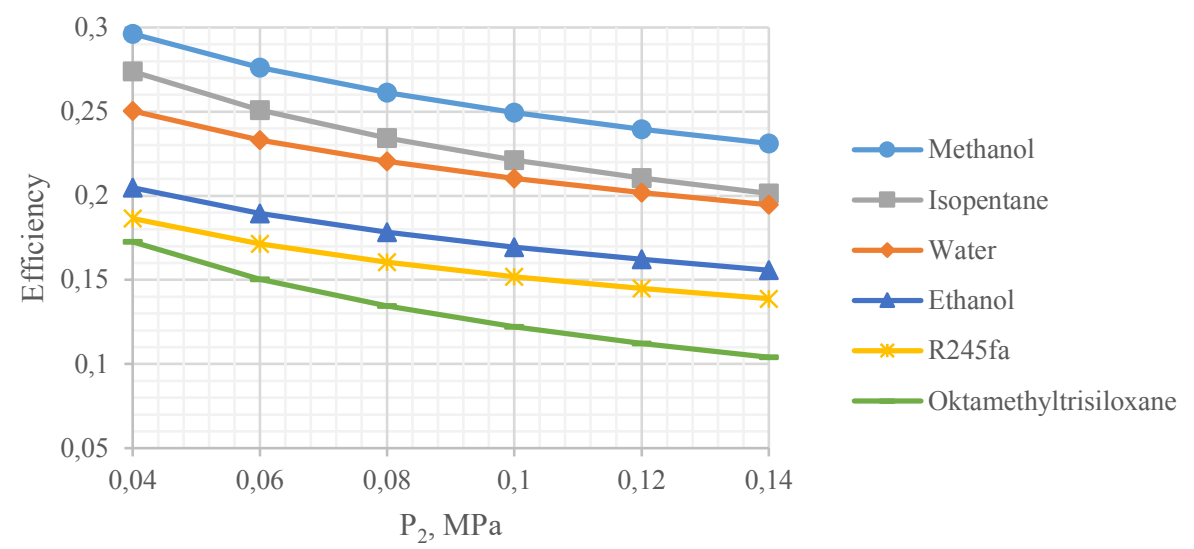

Fig. 2. Dependence of efficiency on the turbine outlet pressure at $\mathrm{T} 0=550 \mathrm{~K}, \mathrm{p} 0=3.6 \mathrm{MPa}$.

Nevertheless, when choosing the working fluid for implementation in ORC, one cannot procced only from thermal efficiency considerations. The problem of optimal substance determination is multicriteria. In particular, heat exchanger area, turbine dimensions, cost of installation and its operation need to be taken into account. Thus, economic considerations may determine other characteristics of the working fluid different from those that were obtained after thermodynamic analysis. There are a lot of substances considered in the literature that can be used as working fluid in ORC turbine but only few of them are used in commercial turbine installations. That is why, ethanol was chosen in addition to isopentane as it has a positive experience of use in foreign studies [12].

To evaluate geometric, gas dynamic and thermodynamic parameters of designed turbine preliminary calculation of the engine was carried out. Determination of the nozzles height, power available, characteristic number $u / C_{0}$ depending on the average turbine wheel diameter was conducted using the program developed at the Turbines, Hydro Machines and Aircraft Engines department of Peter the Great St. Petersburg Polytechnic University. This program is designed to calculate the supersonic single-stage microturbine of the LPI (Leningrad Politechnic Institute)design. One of the main features of the LPI design turbine is small outlet angle of the nozzle blade cascade $\alpha_{1 b}=3 \ldots 9^{\mathrm{O}}$. To design an impulse stage, the degree of reaction was chosen equal to 0.05 . The height of the blade was chosen in such a way that $D_{c p} / l$ was greater than 8 . This condition allows to design the blades with radial forming active surfaces. With a full supply of the working fluid, the height of the blade is too small $\left(l_{l}<1 \mathrm{~mm}\right)$, which leads to large tip losses. This can be avoided with partial admission of the working fluid. Inlet parameters of gas were taken on the basis of trucks combustion engines exhaust gases data $[10,12]$.

Dependence of characteristic number $u / C_{0}$ on the average turbine wheel diameter obtained for isopentane and ethanol (Fig. 3) allows to evaluate the maximum efficiency for given values of the mass flow rate, and velocity rate in blade and nozzle wheels $(\mu, \varphi, \psi)$ by the formula (2):

$$
\eta_{u}=2 \frac{u}{C_{0}}\left\{\left[\varphi \cos \alpha_{1} \sqrt{1-\left(\frac{u}{C_{0}}\right)^{2}\left(1-\mu^{2}\right)}-\frac{u}{C_{0}}\right]\left[1+\mu \psi \frac{\cos \beta_{2}^{*}}{\cos \beta_{1}}\right]+\frac{u}{C_{0}}\left(1-\mu^{2}\right)\right\},
$$

where $\alpha_{1}$ - nozzle assembly inlet flow angle, $\beta_{1}$ - blade wheel inlet flow angle, $\beta_{2}^{*}$ - blade wheel outlet flow angle; accept that $\frac{\cos \beta_{2}^{*}}{\cos \beta_{1}}=1 ; \varphi=0.894, \psi=0.906$ [16].

Efficiency graphs (Fig. 4) show that ethanol has 2\% higher efficiency. This fact determines the choise of ethanol for further investigation and design of the turbine. 


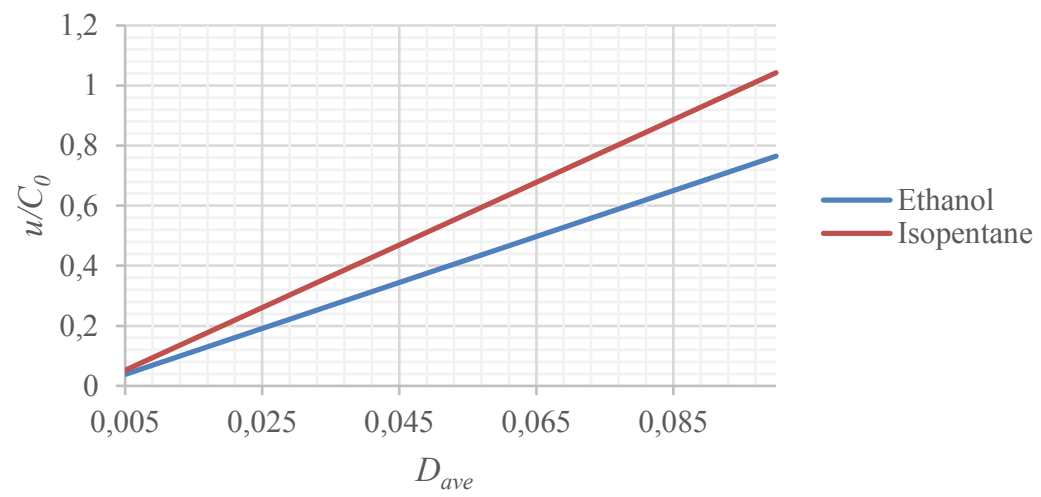

Fig. 3. Dependence of characteristic number $u / C_{0}$ on the average turbine wheel diameter.
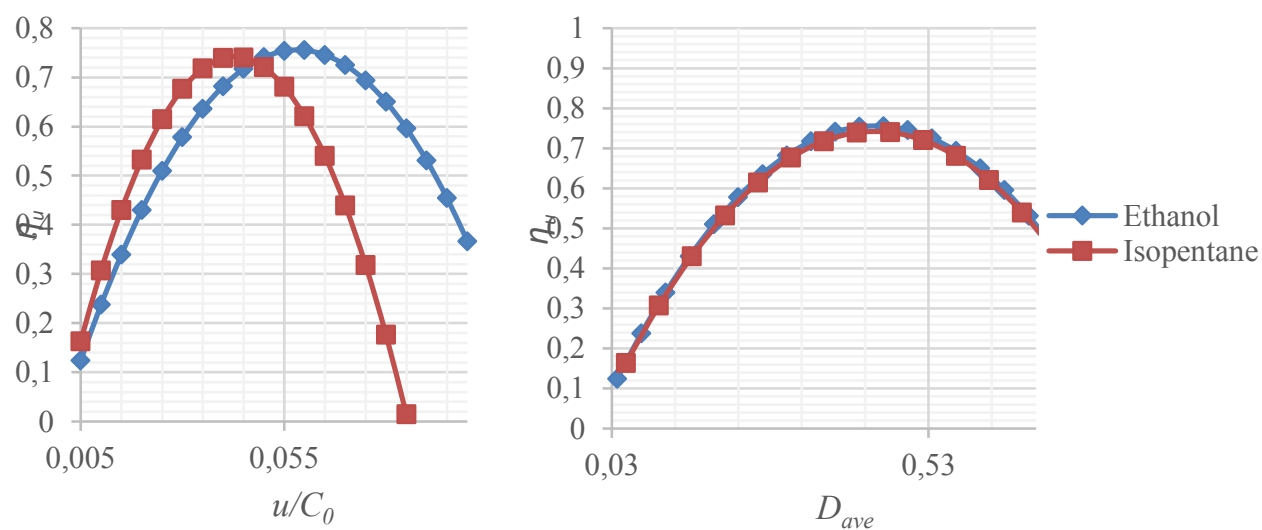

Fig. 4. Dependence of efficincy on the characteristic number $u / C_{0}$ and average turbine wheel diameter.

Preliminary parameters of the turbine designed for ethanol are presented in the Table 1. Combustion engine exhaust gases heat recovery turbine has average diameter $60.4 \mathrm{~mm}$ and vane height $3.2 \mathrm{~mm}$. Operating rotation speed $-105000 \mathrm{rev} / \mathrm{min}$. Partial admission degree $70 \%$ in operating point. Characteristic number $u / C_{0}$ equal 0.46 corresponds to the single-stage turbine.

Table 1. Preliminary turbine parameters.

\begin{tabular}{|c|c|c|c|}
\hline & Symbol & Dimension & Value \\
\hline Power available & $N_{a v}$ & $\mathrm{~W}$ & 11494.0 \\
\hline Average diameter & $D_{a v e}$ & $\mathrm{~mm}$ & 60.4 \\
\hline Characteristic number & $u / C_{0}$ & - & 0.46 \\
\hline Vane height & $l_{l}$ & $\mathrm{~mm}$ & 3.2 \\
\hline Partial admission degree & $\varepsilon$ & - & 0.7 \\
\hline Number of nozzles & $z_{c}$ & $\mathrm{pcs}$ & 2 \\
\hline Nozzle throat & $D_{\min }$ & $\mathrm{mm}$ & 1.0 \\
\hline Rotation speed & $n$ & $\mathrm{rev} / \mathrm{min}$ & 105000.0 \\
\hline
\end{tabular}


Turbine optimization was carried out with mathematic model based on kinetic energy loss experimental characteristics in blades and nozzles wheels, which were studied in the wide range of geometric and operating parameters. Single-stage LPI design micro turbine mathematic model is a complete modeling algorithm composed of separate blocks in which processes in the flow passage of the turbine are described taking into account their connections and mutual influence. Flow passage part block model contains the basic equations describing thermogasdynamic processes, the submodel for determining energy and mass flow loss coefficients, as well as computational procedures for solving equations, approximation and logical deployment [16]. This optimization work allowed obtaining the main parameters of the turbine (Table 2), such as: blade height $h_{b}=7 \mathrm{~mm}$; nozzle assembly geometric expansion degree $f_{c}=F_{\text {out }} / F_{\text {critical }}=1$; nozzle assembly geometric inlet angle $\alpha_{l g}=5 \mathrm{deg}$; number of nozzles $Z_{n}=18$; trailing edge thickness $\Delta_{\text {edge }}=0.3 \mathrm{~mm}$. This data are necessary for further profiling of the turbine stage.

Table 2. Main turbine parameters.

\begin{tabular}{|c|c|c|c|c|}
\hline$\#$ & & Symbol & Dimension & Value \\
\hline 1 & Degree of the reaction & $\rho_{t}$ & - & 0.166 \\
\hline 2 & Mach number in nozzle assembly & $M_{l t}$ & - & 2.634 \\
\hline 3 & Static pressure at the turbine outlet & $P_{2}$ & $\mathrm{~Pa}$ & 81000 \\
\hline 4 & Total temperature in relative frame & $T_{1}{ }^{*}$ & $\mathrm{~K}$ & 403.9 \\
\hline 5 & $\begin{array}{c}\text { Blade wheel outlet Mach number in } \\
\text { relative frame }\end{array}$ & $M_{2 t}$ & - & 1.825 \\
\hline 6 & Blade wheel outlet velocity & $C_{2}$ & $\mathrm{~m} / \mathrm{s}$ & 208.0 \\
\hline 7 & Power of turbine & $N^{2}$ & $\mathrm{~kW}$ & 12.19 \\
\hline 8 & Power available & $N_{a v}$ & $\mathrm{~kW}$ & 18.64 \\
\hline 9 & Efficiency ratio & $H_{B}$ & - & 0.654 \\
\hline 10 & Total efficiency ratio & $h^{*}$ & - & 0.721 \\
\hline 11 & Outlet total temperature & $T_{2}{ }^{*}$ & $\mathrm{~K}$ & 322.9 \\
\hline 12 & Outlet total pressure & $P_{2}^{*}$ & $\mathrm{~Pa}$ & 119057.9 \\
\hline 13 & Mass flow & $G$ & $\mathrm{~kg} / \mathrm{s}$ & 0.052 \\
\hline
\end{tabular}

Based on the geometric data obtained in the calculation and subsequent optimization, a turbine model was designed (Fig. 5, Fig. 6).

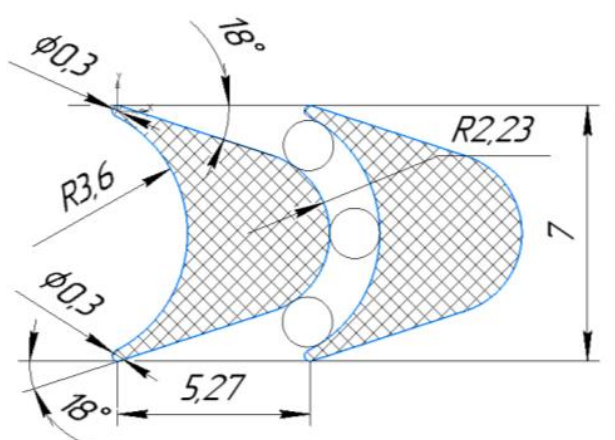

Fig. 5. Blade profile on the average radius. 


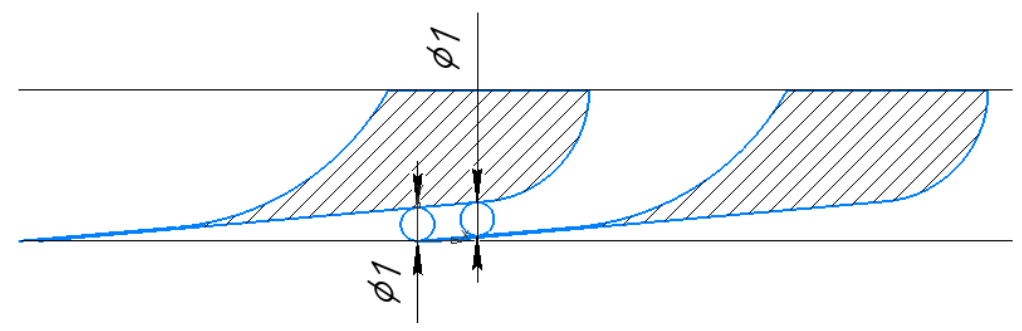

Fig. 6. Nozzle profile on the average radius.

\section{Results and Discussion}

As a result of the work performed, the possibility of creating a microturbine installation with an LPI design stage for combustion engine exhaust gases heat recovery was shown. A study was conducted on the choice of the optimal working fluid. Ethanol has demonstrated the best parameters from thermodynamic and economic points of view. Microturbine stage was developed for the following parameters of the working fluid: $P_{0}=3.6 \mathrm{MPa}, T_{0}=530 \mathrm{~K}$, $n=105000 \mathrm{rev} / \mathrm{min}, G=0.052 \mathrm{~kg} / \mathrm{s}$.

Design and optimization were carried out according to the methods developed at the Turbines, Hydro Machines and Aircraft Engines department of Peter the Great St. Petersburg Polytechnic University. The efficiency of the turbine stage is quite high and equal to 0.645 in static parameters and 0.721 in total parameters. The analysis shows that the LPI design turbine stage is effective and allows to develop reccomendatons for designing and optimizing the turbine stage. Designed stage will reduce gas emission fron the combustion engine and increase the power for customer needs, efficiency and environmental friendliness of the engine. Nevertheless, theoretical calculations even based on empirical equations and existing experience in designing such turbines must be verified in practice. For this propose, it is planned to further study this stage on the test rig. Numerical simulations will also be carried out to reduce the cost of a practical experiment.

\section{Conclusions}

Upon completion of the research work, the findings and recommendations on the development of principles for the construction of the microturbine with low-flow LPI design turbine stage for combustion engine exhaust gases heat recovery can be used in the creating and commissioning of this type of turbines. This is relevant for Russian market given low prevalence of such turbines and the lack of research in this area.

Also a subsequent study based on numerical simulation and its verification with field tests can be used to reduce the cost of the development, refinement and optimization of a microturbine stage operating in conditions of low volumetric mass flow of the working fluid and high initial parameters of the working fluid, as it will contain recommendations for optimal values at building finite element model.

\section{References}

1. H. Chen, D.Y. Goswami, E.K. Stefanakos, Renewable and Sustainable Energy Reviews 14, 3059- 3067 (2010)

2. B. Saleh, G. Koglbauer, M. Wendland, J. Fischer, Energy 32, 1210-1221 (2007)

3. U. Drescher, D. Brüggemann, Applied Thermal Engineering 27, 223-228 (2007) 
4. B.F. Tchanche, G. Papadakis, G. Lambrinos, A. Frangoudakis, Applied Thermal Engineering 29 (11-12), 2468- 2476 (2009)

5. D. Mikielewicz, J. Mikielewicz, Applied Thermal Engineering 30, 2357- 2362 (2010)

6. A.A. Lakew, O. Bolland, Applied Thermal Engineering 30, 1262-1268 (2010)

7. M.Z. Stijepovic, P. Linke, A.I. Papadopoulos, A.S. Grujic, Applied Thermal Engineering 36, 406-413 (2012)

8. Z.Q. Wang, N.J. Zhou, J. Guo, X.Y. Wang, Energy 40 (1), 107-115 (2012)

9. H. Oomori, S. Ogino, SAE Technical Paper, 930880 (1976)

10. P. Patel, E. Doyle, SAE Technical Paper, 760343 (1976)

11. R. El Chammas, D. Clodic, SAE Technical Paper, 2005-01-1171 (2005)

12. Harald Kunte, Joerg Seume, SAE Technical Paper 2013-24-0092 (2013)

13. H.E. Dillon, S.G. Penoncello, Int. J. Thermophys. 25(2), 321-335 (2004)

14. K.M. de Reuck, R.J.B. Craven, Methanol, International Thermodynamic Tables of the Fluid State - 12. IUPAC, Blackwell Scientific Publications, London (1993)

15. W. Wagner, A. Pruss, J. Phys. Chem. 31(2), 387-535 (2002)

16. V. Rassokhin, V. Busurin, V. Sadovnichy. Design and milti-mod optimization of lowflow turbines. Innovative high technologies for Russia, 39 (1995)

17. V.Rassokhin, N. Golovin, V. Sadovnichy, Scientific and Technical Conference RAS (1997)

18. N. Zabelin, G. Rakov, V. Rassokhin, SPbPU Journal of Engineering Science and Technology 1(166) (2013)

19. A. Epifanov, A. Kirillov, V. Rassokhin, SPbPU Journal of Engineering Science and Technology 1(142) (2012)

20. N. Zabelin, G. Rakov, G. Fokin, SPbPU Journal of Engineering Science and Technology 3(178) (2013)

21. G.V. Belov, M.A. Dorokhova, Science and education: scientific publication of MGTU Baumana 2, 99-124 (2014)

22. V.I. Gorynin, S.Y. Kondrat'ev, M.I. Olenin, V.V. Rogozhkin, Metal Science and Heat Treatment 56, 548-554 (2015), doi:10.1007/s11041-015-9797-2

23. V.V. Davydov, Optics and Spectroscopy (English translation of Optika i Spektroskopiya) 121, 18-24 (2016), doi:10.1134/S0030400X16070092

24. M.R. Petritchenko, E.V. Kotov, D.V. Nemova, D.S. Tarasova, V.V. Sergeev, Magazine of Civil Engineering 77, 130-140 (2018), doi:10.18720/MCE.77.12

25. N. Vatin, A. Gorshkov, D. Nemova, O. Gamayunova, D. Tarasova, AMM, 670-671, 349-354 (2014), doi:10.4028/www.scientific.net/AMM.670-671.349

26. A.V. Karavan, A.E. Bolotin, Teoriya i Praktika Fizicheskoy Kultury 2015-Janua, 5-7 (2015)

27. M.V. Petrochenko, K.I. Strelets, M.R. Petrichenko, E.B. Yavtushenko, AMM, 672674, 567-570 (2014), doi:10.4028/www.scientific.net/AMM.672-674.567

28. M.V. Silnikov, M.V. Chernyshov, A.I. Mikhaylin, Acta Astronautica 109, 235-240 (2015), doi:10.1016/j.actaastro.2014.12.007

29. A. Gorshkov, N. Vatin, D. Nemova, A. Shabaldin, L. Melnikova, P. Kirill, Procedia Engineering 117, 1085-1094 (2015), doi:10.1016/j.proeng.2015.08.240 